\title{
Positive end-expiratory pressure improves elastic working pressure in anesthetized children
}

Pablo Cruces ${ }^{1,2}$, Sebastián González-Dambrauskas ${ }^{3}$, Federico Cristiani ${ }^{4}$, Javier Martínez ${ }^{3}$, Ronnie Henderson ${ }^{4}$, Benjamin Erranz ${ }^{5}$ and Franco Díaz $z^{5,6,7^{*}}$

\begin{abstract}
Background: Positive end-expiratory pressure (PEEP) has been demonstrated to decrease ventilator-induced lung injury in patients under mechanical ventilation (MV) for acute respiratory failure. Recently, some studies have proposed some beneficial effects of PEEP in ventilated patients without lung injury. The influence of PEEP on respiratory mechanics in children is not well known. Our aim was to determine the effects on respiratory mechanics of setting PEEP at $5 \mathrm{cmH}_{2} \mathrm{O}$ in anesthetized healthy children.

Methods: Patients younger than 15 years old without history of lung injury scheduled for elective surgery gave informed consent and were enrolled in the study. After usual care for general anesthesia, patients were placed on volume controlled MV. Two sets of respiratory mechanics studies were performed using inspiratory and expiratory breath hold, with PEEP 0 and $5 \mathrm{cmH}_{2} \mathrm{O}$. The maximum inspiratory and expiratory flow $\left(\mathrm{Q}_{1}\right.$ and $\left.\mathrm{Q}_{\mathrm{E}}\right)$ as well as peak inspiratory pressure (PIP), plateau pressure $\left(\mathrm{P}_{\mathrm{PL}}\right)$ and total PEEP (tPEEP) were measured. Respiratory system compliance $\left(\mathrm{C}_{\mathrm{RS}}\right)$, inspiratory and expiratory resistances (Rawl and RawE) and time constants ( $\mathrm{K}_{\mathrm{TI}}$ and $\left.\mathrm{K}_{\mathrm{TE}}\right)$ were calculated. Data were expressed as median and interquartile range (IQR). Wilcoxon sign test and Spearman's analysis were used. Significance was set at $P<0.05$.

Results: We included 30 patients, median age 39 (15-61.3) months old, 60\% male. When PEEP increased, PIP increased from $12(11,14)$ to $15.5(14,18)$, and $C_{R S}$ increased from $0.9(0.9,1.2)$ to $1.2(0.9,1.4) \mathrm{mL} \cdot \mathrm{kg}^{-1} \cdot \mathrm{cmH}_{2} \mathrm{O}^{-1}$; additionally, when PEEP increased, driving pressure decreased from $6.8(5.9,8.1)$ to $5.8(4.7,7.1) \mathrm{cmH}_{2} \mathrm{O}$, and $\mathrm{Q}_{E}$ decreased from $13.8(11.8,18.7)$ to $11.7(9.1,13.5) \mathrm{L} \cdot \mathrm{min}^{-1}$ (all $\left.P<0.01\right)$. There were no significant changes in resistance and $\mathrm{Q}_{1}$.

Conclusions: Analysis of respiratory mechanics in anesthetized healthy children shows that PEEP at $5 \mathrm{cmH}_{2} \mathrm{O}$ places the respiratory system in a better position in the PN curve. A better understanding of lung mechanics may lead to changes in the traditional ventilatory approach, limiting injury associated with MV.
\end{abstract}

Keywords: Positive end-expiratory pressure, Mechanical ventilation, Respiratory mechanics, Pediatrics

* Correspondence: francodiazr@gmail.com

5Unidad de Cuidados Intensivos Pediátricos, Clínica Alemana de Santiago,

Avda. Vitacura, 5951 Santiago, Chile

${ }^{6}$ Facultad de Medicina Clínica Alemana Universidad del Desarrollo, Santiago,

Chile

Full list of author information is available at the end of the article

(c) The Author(s). 2018 Open Access This article is distributed under the terms of the Creative Commons Attribution 4.0 International License (http://creativecommons.org/licenses/by/4.0/), which permits unrestricted use, distribution, and reproduction in any medium, provided you give appropriate credit to the original author(s) and the source, provide a link to the Creative Commons license, and indicate if changes were made. The Creative Commons Public Domain Dedication waiver (http://creativecommons.org/publicdomain/zero/1.0/) applies to the data made available in this article, unless otherwise stated. 


\section{Background}

There are many detrimental effects of positive pressure mechanical ventilation (MV) to the lung parenchyma, giving shape to the entity we know as ventilator induced lung injury (VILI) $[1,2]$. Despite that it was initially described for injured lungs [3], VILI has been recognized to affect patients with uninjured lungs, triggering many pathways of local and systemic inflammation [1-4]. Positive pressure MV can cause VILI even when applied for short periods of time, and the role of protective MV during anesthesia has become important for preventing postoperative complications [5-10]. Although the exact incidence of VILI during general anesthesia is unknown, the lungs of patients under general anesthesia are especially vulnerable to VILI, since anesthetic induction reduces the end expiratory lung volume (EELV) by $9-25 \%$ in adults and up to $46 \%$ in children [11-15]. Cyclic opening and collapsing of alveoli have been indicated as one of the primary mechanisms of VILI during anesthesia. Imaging studies have shown that general anesthesia induces atelectasis of dependent regions and that the use of PEEP prevents its formation $[3,5,9,10,14]$. Protective ventilation during general anesthesia $[16,17]$ to limit tidal volume $(6-8 \mathrm{ml} / \mathrm{kg})$ has been widely accepted and incorporated into the operating room (OR), but PEEP use is still not a common practice for patients undergoing general anesthesia [6-10, 17, 18].

In the absence of respiratory muscle activity, working pressure of the respiratory system is the pressure needed to overcome frictional forces, elastic forces and impedance. In this way, an improvement in CRS reflects lower elastic work pressures and, therefore, a pending situation of its more favorable dynamic pressure/volume curve (P/V curve) [19]. These observations also have been described in pediatric animal models [20, 21].

There is little evidence to guide MV during general anesthesia in children $[18,22,23]$. MV parameters are primarily dependent on anesthesiologist preferences and on the characteristics of anesthesia machines [24]. Facing this scenario, many scientific societies have pointed as priority areas of research to the pathophysiology, respiratory mechanics and practice of MV in children for improving outcomes and reducing secondary long-term lung injury [23].

With these facts in mind, we sought to compare respiratory mechanics of setting PEEP at $5 \mathrm{cmH}_{2} \mathrm{O}$ compared to ZEEP (PEEP set at $0 \mathrm{cmH}_{2} \mathrm{O}$ ) in anesthetized children without acute pulmonary pathology undergoing elective surgery. We hypothesized that usual respiratory mechanics parameters, measured with a commercial mechanical ventilator, would identify a more protective ventilation with addition of PEEP $5 \mathrm{cmH}_{2} \mathrm{O}$. Special emphasis was placed on evaluation on respiratory work pressure, flow patterns, resistance and inspiratory and expiratory time constants.

\section{Methods}

\section{Study design and setting}

This prospective study was conducted at the Surgical Block of Centro Hospitalario Pereira Rossell located in Montevideo, Uruguay. The local ethic committee approved the study and informed consent was obtained for each patient before entering the OR.

\section{Study population}

Between February 1, 2015 and April 30, 2016, children younger than 15 years old without preexisting lung injury scheduled for elective surgery were screened for the study. For definitive selection, patients categorized as ASA I or II, requiring orotracheal intubation for the surgery according to the anesthesiologist's criteria, were considered. Patients were excluded if they had any acute condition before or during anesthesia (e.g., laryngospasm, bronchoconstriction, pneumothorax), thoracic surgery, thoracic or airway malformation and chronic lung disease with oxygen dependence. Additionally, patients with endotracheal tube air leak $>20 \%$ of tidal volume $\left(\mathrm{V}_{\mathrm{T}}\right)$ were excluded due to possible interference with data acquisition.

\section{Data collection}

We registered demographics and clinical information at admission. All procedures before respiratory system mechanics measurements were done according to institutional protocol and anesthesiologist preferences, including anesthesia induction, orotracheal intubation and initial ventilatory settings on the anesthesia machine.

\section{Study protocol}

Patients were ventilated on a Galileo Gold $^{\circledR}$ ventilator (Hamilton, Bonaduz, Switzerland) on volume control mode after verification of correct positioning of the endotracheal tube. Baseline settings were as follows: $\mathrm{V}_{\mathrm{T}}=6-$ $8 \mathrm{~mL} \cdot \mathrm{kg}^{-1}, \mathrm{PEEP}=5 \mathrm{cmH}_{2} \mathrm{O}$, fraction of inspired oxygen $\left(\mathrm{FiO}_{2}\right)$ was adjusted to a target pulse oximetry greater than $95 \%$, inspiratory: expiratory ratio $=1: 2$, and respiratory rate $(\mathrm{RR})$ was adjusted to achieve an end-tidal carbon dioxide $\left(\mathrm{ETCO}_{2}\right) 40 \pm 5 \mathrm{mmHg}$. Tracheal tube leak compensation was deactivated through the measurements.

\section{Respiratory mechanics measurements}

Two sets of measurements were performed, at ZEEP and PEEP $5 \mathrm{cmH}_{2} \mathrm{O}$, separated by $5 \mathrm{~min}$ of stability, following local protocol for respiratory mechanics measurements. This protocol is summarized in Additional file 1 [19]. All measurements were made in pre-incision surgical time.

Ventilator parameters [peak inspiratory pressure (PIP), plateau pressure $\left(\mathrm{P}_{\mathrm{PL}}\right)$, extrinsic (set) PEEP (PEEP), total PEEP (tPEEP), intrinsic PEEP (iPEEP = tPEEP - PEEP), driving pressure $\left(\Delta \mathrm{P}=\mathrm{P}_{\mathrm{PL}}-\mathrm{tPEEP}\right)$, mean airway pressure expiratory (Paw), $\mathrm{V}_{\mathrm{T}}$, inspiratory time (IT), 
respiratory rate $(\mathrm{RR})$, maximum inspiratory and expiratory flow $\left(\mathrm{Q}_{\mathrm{I}}\right.$ and $\left.\mathrm{Q}_{\mathrm{E}}, \mathrm{L} \cdot \mathrm{min}^{-1}\right)$ ] were assessed. An inspiratory hold followed by an expiratory hold was performed following the protocol described in Additional file 1. Flow and pressure parameters in these quasi-static conditions at the $\mathrm{Y}$ piece (proximal flow sensor) were recorded in an ad hoc Microsoft Excel 2010 (Microsoft ${ }^{\ominus}$, NY, USA) database to calculate respiratory system compliance $\left(C_{R S}\right.$, $\left.\mathrm{mL} \cdot \mathrm{cmH}_{2} \mathrm{O}^{-1} \cdot \mathrm{kg}^{-1}\right)$, inspiratory and expiratory airway resistance (RawI and RawE, $\mathrm{cmH}_{2} \mathrm{O} \cdot \mathrm{L}^{-1} \cdot \mathrm{s}^{-1}$ ), and inspiratory and expiratory time constants $\left(\mathrm{K}_{\mathrm{TI}}\right.$ and $\left.\mathrm{K}_{\mathrm{TE}}, \mathrm{s}\right)$ according to formulas described in Additional file 2.

\section{Data analysis}

Data are expressed as median and interquartile range (IQR). A previous study found that changing PEEP from 0 to $12 \mathrm{cmH}_{2} 0$ resulted in a decrease in dynamic compliance (Cdyn) in $9.4 \mathrm{ml} / \mathrm{cmH}_{2} \mathrm{O}$ with SD 6.8 [25]. Given the fact that our protocol included a moderate modification of PEEP, from 0 to $5 \mathrm{ml} / \mathrm{cmH}_{2} \mathrm{O}$, we expected a smaller change of Cdyn, $2 / 3$ of previously described [25]. A sample size of 30 patients is needed to determine a variation of Cdyn by $6 \mathrm{ml} / \mathrm{cmH}_{2} \mathrm{O}$, using chi-square test and assuming an $\alpha$ of 0.05 and a power of $90 \%$. Normality was assessed with the Anderson-Darling test. Wilcoxon sign test was performed for comparisons between respiratory mechanics assessments. Spearman's analysis was used to examine correlations between changes in respiratory mechanics and age and ideal body weight. Differences were considered significant if $p<0.05$. All statistical analyses were performed using SPSS 20.0 (SPSS Inc., Chicago, IL, USA). Figures were plotted with GraphPad Prism version 5.0c for Mac (GraphPad Software, La Jolla, CA, USA).

\section{Results}

Thirty patients were included in the study. Sixty percent were male, the median age was 39 months (15-61.3), and weight was $15 \mathrm{~kg}$ (10.6-21).

Sixty percent of patients received inhaled anesthesia and $40 \%$ mixed inhalation and intravenous anesthesia. Abdominal surgery was the most frequent (20 cases), mostly hernioplasty. Malformation of the digestive tract was the most frequent comorbidity, present in 7 patients. Table 1 shows clinical characteristics of included patients.

There were no complications related to the protocol. Table 2 shows ventilatory parameters and respiratory system mechanics for the study population with ZEEP and PEEP of $5 \mathrm{cmH}_{2} \mathrm{O}$. After setting PEEP at $5 \mathrm{cmH}_{2} \mathrm{O}$ we observed an increase in PIP, $\mathrm{P}_{\mathrm{PL}}$ and Paw, with a concomitant decrease in iPEEP and $\triangle \mathrm{P}$. Figure 1 shows individual changes on $\Delta \mathrm{P}$ throughout the study. No modifications were done on $\mathrm{V}_{\mathrm{T}}$, and thus, changes on $\Delta \mathrm{P}$ were coupled to variation on $\mathrm{C}_{\mathrm{RS}}$.
There was a moderate correlation between age and ideal body weight and changes in $\mathrm{Q}_{\mathrm{E}}$ and changes in $K_{\mathrm{TE}}$. Additional file 3 shows the correlation between changes in respiratory parameters and age and ideal body weight. No other correlations with age and weight were found.

\section{Discussion}

In this study, we measured pulmonary mechanics in anesthetized healthy children on MV for elective surgery at ZEEP and PEEP $5 \mathrm{cmH}_{2} \mathrm{O}$ using a commercially available mechanical ventilator. Setting PEEP at $5 \mathrm{cmH}_{2} \mathrm{O}$ resulted in a significant decrease in $\triangle \mathrm{P}$ and $\mathrm{PPEEP}$, thereby improving $\mathrm{C}_{\mathrm{RS}}$. Changes observed in respiratory mechanics after setting PEEP at $5 \mathrm{cmH}_{2} \mathrm{O}$ are summarized in Fig. 2.

We also found a decrease in $\mathrm{QE}_{E}$ when PEEP was applied. All these findings are indirect signs of lungs in a better position in dynamic $\mathrm{P} / \mathrm{V}$ curve, suggesting that the addition of a low level of PEEP improves respiratory mechanics.

The effect of PEEP on patients with ARDS was described more than a decade ago, promoting recruitment of non-aerated lung volume and increasing EELV. More recently, many investigators have shown that PEEP should be incorporated to lung protective strategy during the perioperative period in patients at risk for ARDS as well as previously healthy patients $[6,8-10]$. In this setting, hypoxemia was not associated with the reduction in EELV, and thus, hypoxemia is thought to be a poor predictor of potential injurious MV. Similar findings have been described in children. Serafini et al. described densities in dependent regions of both lungs on CT scan of 10 infants after induction of anesthesia. They observed reopening of the collapsed lung with addition of $5 \mathrm{cmH}_{2} \mathrm{O}$ of PEEP for 5 min [14]. Kadini et al., in a small study of 8 anesthetized children (range between 2.5 and 6.5 years old), described that $5 \mathrm{cmH}_{2} \mathrm{O}$ resulted in a significant increase of VT; thus, $\mathrm{C}_{\mathrm{RS}}$ improved [24].

Our results show that the addition of PEEP sets the respiratory system in a better position of the P/V curve, probably related to the reduction of the atelectasis in lung dependent zones after induction of anesthesia and MV with ZEEP. An increase in EELV, maintaining the same $V_{T}$, denotes a reduction in global strain and, potentially, VILI [26].

$\triangle \mathrm{P}$ has taken high priority after the recent pooled data analysis of adult patients with ARDS that showed a significant relationship with mortality [27]. $\Delta \mathrm{P}$ represents the pressure required for the movement of inspiratory flow and depends on the lung and chest wall viscoelastic resistance [28]. Recently, Neto et al. in a meta-analysis of 2250 patients under general anesthesia found that high $\Delta \mathrm{P}$ was the only $\mathrm{MV}$ parameter associated with postoperative complications [29]. Even more, they found 
Table 1 Clinical characteristics of children included in the study

\begin{tabular}{|c|c|c|c|c|c|}
\hline Number & Age (mo) & Weight (kg) & Height $(\mathrm{cm})$ & Surgery & Comorbidities \\
\hline 1 & $40-50$ & 17.5 & 105 & Inguinal hernia & none \\
\hline 2 & $40-50$ & 16.7 & 105 & Umbilical hernia & none \\
\hline 3 & $30-40$ & 13 & 90 & Cryptorchid & none \\
\hline 4 & $10-20$ & 5.1 & 67 & CVL placement & Short bowel insufficiency \\
\hline 5 & $30-40$ & 15 & 94 & Anorectoplasty & Partial anomalous venous return \\
\hline 6 & $40-50$ & 15 & 94 & Inguinal hernia & Asthma \\
\hline 7 & $20-30$ & 11.2 & 82 & Epigastric hernia & none \\
\hline 8 & $10-20$ & 9.2 & 70 & Enterostomy closure & Imperforated anus \\
\hline 9 & $50-60$ & 18 & 101 & Enterostomy closure & Colostomy \\
\hline 10 & $60-70$ & 14.2 & 104 & Esophageal dilatation & Esofageal coloplasty \\
\hline 11 & $50-60$ & 26 & 114 & Abdominal tumor & none \\
\hline 12 & $30-40$ & 22 & 99 & Hidrocele & none \\
\hline 13 & $50-60$ & 19 & 90 & Fimosis & none \\
\hline 14 & $30-40$ & 23 & 103 & Cryptorchid & none \\
\hline 15 & $20-30$ & 11.9 & 81 & Inguinal hernia & none \\
\hline 16 & $70-80$ & 24.6 & 120 & Cryptorchid & none \\
\hline 17 & $3-10$ & 7 & 63 & Inguinal hernia & none \\
\hline 18 & $10-20$ & 10.4 & 77 & Inguinal hernia & none \\
\hline 19 & $10-20$ & 13.5 & 80 & Cryptorchid & none \\
\hline 20 & $120-130$ & 25.8 & 132 & Colecystectomy & none \\
\hline 21 & $3-10$ & 5.7 & 62 & Inguinal hernia & none \\
\hline 22 & $140-150$ & 40 & 154.5 & Thyroidectomy & none \\
\hline 23 & $3-10$ & 4.9 & N/A & Eventration repair & Traumatic eventration \\
\hline 24 & $80-90$ & 19.7 & 116 & Enterostomy closure & Hirschprung's Disease \\
\hline 25 & $80-90$ & 27 & 118 & Enterostomy closure & Hirschprung `sDisease \\
\hline 26 & $110-120$ & 29 & 129.5 & Anoplasty & Anorectal Malformation \\
\hline 27 & $100-110$ & 21 & 116 & CVL placement & Astrocytoma \\
\hline 28 & $10-50$ & 14 & 103 & Anoplasty & Anorectal malformation \\
\hline 29 & $1-10$ & 4.6 & 56.5 & Exploratory laparoscopy & none \\
\hline 30 & $10-20$ & 7.3 & 77 & CVL placement & Lymphoblastic leukemia \\
\hline
\end{tabular}

mo months old, CVL central venous line, N/A non-available

that changes in PEEP that resulted in an increase in $\triangle \mathrm{P}$ were associated with more postoperative pulmonary complications. It is not surprising that in these studies, $\Delta \mathrm{P}$ was the best predictor of unfavorable outcomes. We believe that the best performance of this parameter is because it integrates the set tidal volume and the patient's compliance, thus giving a more precise idea of the individual conditions of each patient.

In our patients, we observed a $14.8 \%$ (CI95\% 9.3,20.3\%) reduction of $\triangle \mathrm{P}$ when PEEP of $5 \mathrm{cmH}_{2} \mathrm{O}$ was applied. The range of improvement was very wide and only one patient had a significant increase in $\Delta \mathrm{P}$ (greater than 10\%). These results are in accordance with a study by Wirth et al. They elegantly showed, with electric impedance tomography in 30 anesthetized children, that changing PEEP from 2
$\mathrm{cmH}_{2} \mathrm{O}$ to $5 \mathrm{cmH}_{2} \mathrm{O}$ homogenizes regional lung ventilation [30]. One of our patients had a significant increase of $\Delta \mathrm{P}$. This a very good example that ventilatory settings need to be tailored individually, because adding $5 \mathrm{cmH}_{2} \mathrm{O}$ of PEEP probably led to overdistension in this patient. We maintained the set $\mathrm{V}_{\mathrm{T}}$ after applying PEEP of $5 \mathrm{cmH}_{2} \mathrm{O}$; thus, the reduction of $\Delta \mathrm{P}$ was dependent on the improvement in $C_{R S}$. The improvement in $C_{R S}$ and EELV may be seen as minor, but we believe that even these small changes may have significant consequences during and after surgery, reducing lung inflammation, alteration of gas exchange, among others. Experimental and clinical data have shown that injurious ventilatory parameters can generate detrimental effects, even when applied for short periods of time $[1,2,31,32]$. 
Table 2 Ventilatory parameters and respiratory system mechanics of children under general anesthesia with ZEEP and PEEP of $5 \mathrm{cmH}_{2} \mathrm{O}$

\begin{tabular}{|c|c|c|c|c|c|}
\hline & ZEEP $(n=$ & & PEEP $5(r$ & & $P$ value \\
\hline & MEDIAN & P25, P75 & MEDIAN & P25, P75 & \\
\hline $\mathrm{FiO}_{2}$ & 0.40 & $0.36,0.50$ & 0.40 & $0.36,0.50$ & 1.000 \\
\hline$V_{\mathrm{TE}}$ & 6.79 & $6.18,7.36$ & 6.53 & $5.97,7.20$ & 0.290 \\
\hline RR & 24 & 21,26 & 24 & 21,26 & 1.0 \\
\hline IT & 0.85 & $0.72,1.02$ & 0.85 & $0.72,1.03$ & 1.00 \\
\hline PIP & 12 & 11,14 & 15.5 & $14.0,18.5$ & $<0.01$ \\
\hline$P_{P L}$ & 7.9 & $7.2,9.18$ & 10.95 & $9.7,12.6$ & $<0.01$ \\
\hline Paw & 4.1 & $3.6,4.9$ & 8.5 & $7.9,9.8$ & $<0.01$ \\
\hline$Q_{1}$ & 11 & $8.1,13.1$ & 11 & $8.1,13.1$ & 0.317 \\
\hline $\mathrm{Q}_{\mathrm{E}}$ & 13.8 & $11.8,13.1$ & 11.7 & $9.1,13.5$ & $<0.01$ \\
\hline Rawl & 25.7 & $18.6,34.3$ & 26.4 & $20.1,33.1$ & 0.447 \\
\hline RawE & 28.9 & $21.9,39.4$ & 29.3 & $22.3,42.1$ & 0.629 \\
\hline$C_{R S}$ & 0.96 & $0.89,1.22$ & 1.19 & $0.94,1.39$ & $<0.01$ \\
\hline $\mathrm{K}_{\mathrm{TI}}$ & 0.36 & $0.31,0.48$ & 0.45 & $0.38,0.59$ & 0.004 \\
\hline
\end{tabular}

ZEEP PEEP $0 \mathrm{cmH}_{2} \mathrm{O}, \mathrm{FiO}_{2}$ fraction of inspired oxygen, $V_{T E}$ expiratory tidal volume $\left(\mathrm{mL} \cdot \mathrm{kg}^{-1}\right), R R$ respiratory rate (breath per minute), IT inspiratory time (s), PIP peak inspiratory pressure $\left(\mathrm{cmH}_{2} \mathrm{O}\right), P_{P L}$ plateau pressure $\left(\mathrm{cmH}_{2} \mathrm{O}\right)$, Paw mean airway pressure $\left(\mathrm{cmH}_{2} \mathrm{O}\right), Q_{1}$ peak inspiratory flow $\left(\mathrm{L} \cdot \mathrm{min}^{-1}\right), Q_{E}$ peak expiratory flow, $\left(\mathrm{L} \cdot \mathrm{min}^{-1}\right)$, Rawl inspiratory airway resistance $\left(\mathrm{cmH}_{2} \mathrm{O} \cdot \mathrm{L}^{-1} \cdot \mathrm{s}^{-1}\right)$, RawE expiratory airway resistance $\left(\mathrm{cmH}_{2} \mathrm{O} \cdot \mathrm{L}^{-1} \cdot \mathrm{s}^{-1}\right), \mathrm{C}_{R S}$ static respiratory system compliance $\left(\mathrm{mL} \cdot \mathrm{cmH}_{2} \mathrm{O}^{-1} \cdot \mathrm{kg}^{-1}\right), K_{T I}$ inspiratory time constant (s)
The prolongation of $\mathrm{K}_{\mathrm{TI}}$ and $\mathrm{K}_{\mathrm{TE}}$ with PEEP of 5 $\mathrm{cmH}_{2} \mathrm{O}$ probably reflects mathematical coupling of changes on $\mathrm{C}_{\mathrm{RS}}$ without modifications on airway resistance. In the same way, the observed lower expiratory flow is related to the lower $\Delta \mathrm{P}$. These parameters are indirect markers of improvement on respiratory system mechanics and more protective ventilation.

Our study has some limitations. Respiratory mechanics measurements were done before the surgery, after a short period of applied PEEP; thus, we cannot extrapolate these findings to other surgical timings, e.g., during pneumoperitoneum, when the effect of PEEP preventing lung collapse could be even higher. Due to small size of patients, we did not measure pleural pressure, so we could not determine the contribution of the chest wall to $C_{R S}$. Included patients were heterogeneous and age range is wide, so in the absence of normal reference data, we cannot generalize these results to all pediatric patients (i.e., younger patients have higher chest compliance, being at higher risk for derecruitment of the lung on ZEEP). Finally, we have to acknowledge that setting of MV parameters can directly modify the component of the equation of motion (i.e., $Q_{I}, R R, I: E$ ratio), but we tried to standardize the ventilatory setting during measurements. Despite these limitations, we consider our observation of the effect of PEEP in anesthetized

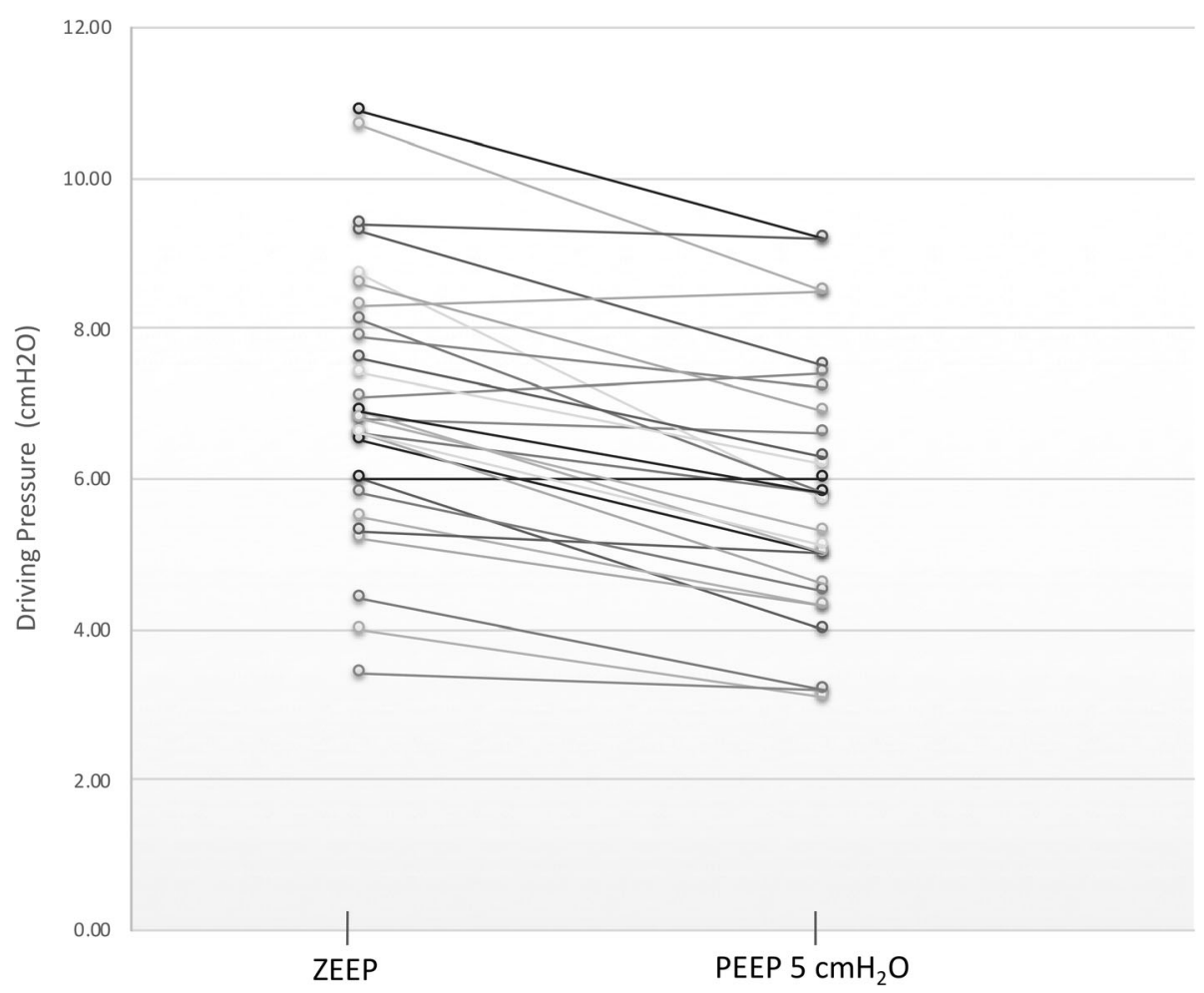

Fig. 1 Individual value plot of driving pressure $\left(\mathrm{cmH}_{2} \mathrm{O}\right)$ with ZEEP and PEEP at $5 \mathrm{cmH}_{2} \mathrm{O}$ in anesthetized healthy children 

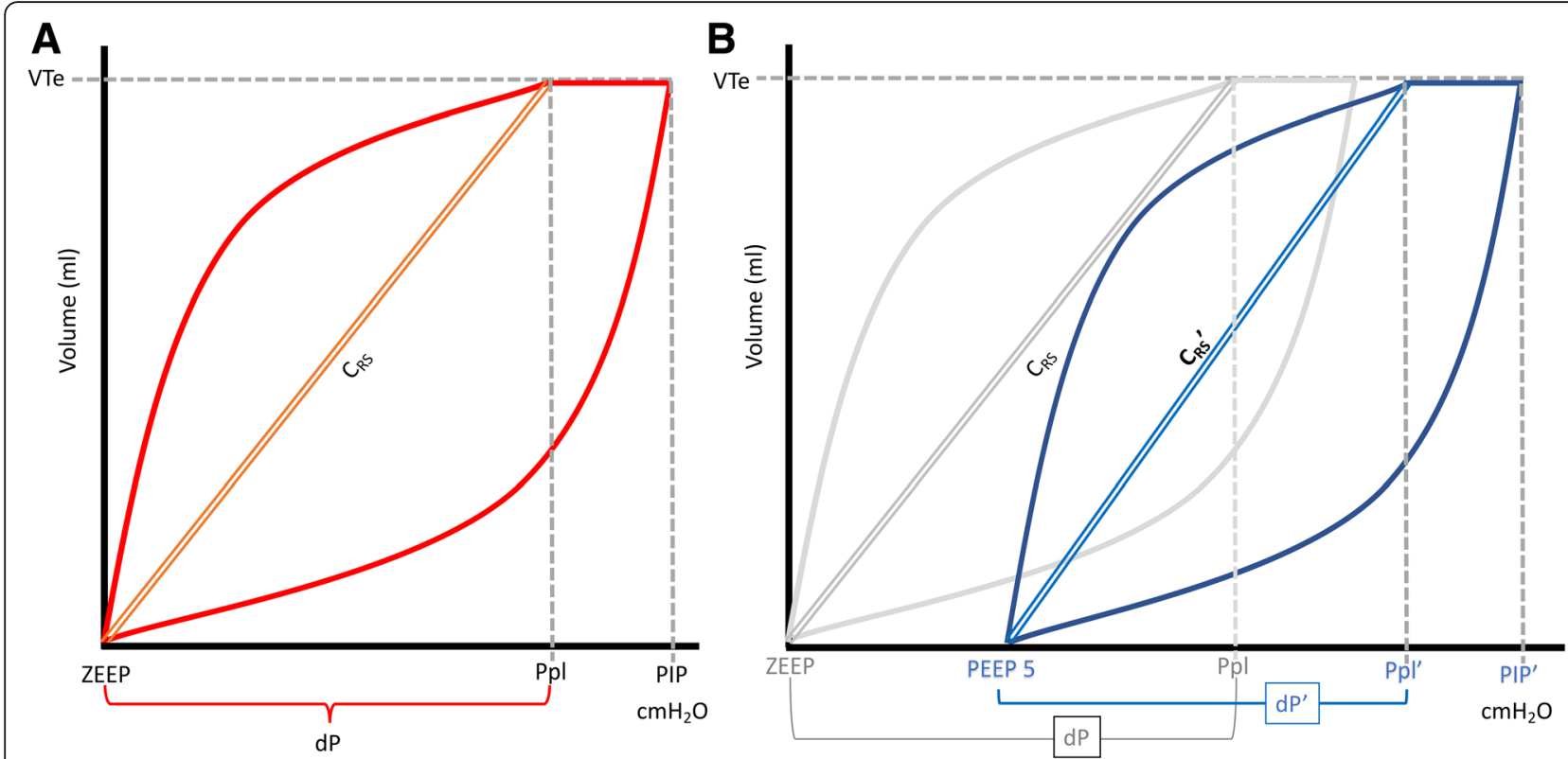

Fig. 2 Pressure - Volume loop (PN curve) sketch summarizing findings of the study: Anesthetized children with ZEEP (panel a) and after setting PEEP at $5 \mathrm{cmH}_{2} \mathrm{O}$ (panel b). PIP, $P_{P L}$ and Paw increased after addition of PEEP of $5 \mathrm{cmH}_{2} \mathrm{O}$ (PIP', $P_{P L}$, , Paw'), but dP decreased (dP'). Given the same $V_{T}, C_{R S}$, represented as the angle of the diagonal line between PEEP and $P_{P L}$ increased $\left(C_{R S}{ }^{\prime}\right)$. All of them are sign of a more efficient working pressures of the respiratory system better position in PN curve. On (panel $\mathbf{b}$ ) respiratory mechanics with ZEEP was added in gray tone as reference

children under mechanical ventilation important in terms of a pathophysiological approach to reduce VILI.

\section{Conclusion}

Setting PEEP at $5 \mathrm{cmH}_{2} \mathrm{O}$ in children during general anesthesia improved elastic working pressure of the respiratory system, decreasing driving pressure and intrinsic PEEP. These findings are indirect signs of lungs in a better position in pressure/volume curve, suggesting that the addition of a low level of PEEP improves respiratory mechanics. These findings may be measured with usual mechanical ventilators and anesthesia machines, analyzing respiratory system mechanics after an inspiratory and expiratory hold. Future studies in infants are needed to address respiratory mechanics during anesthesia, ideally in a specific age group and pathologies with high-risk postoperative complications. A better understanding of respiratory system mechanics in children during general anesthesia may lead to a better titration of mechanical ventilation, preventing VILI.

\section{Additional files}

Additional file 1: Respiratory mechanics measurements. Panel A shows Respiratory mechanics measurement protocol. Panel B shows and illustration of Airway Pressure versus time and flow versus time curves during inspiratory and expiratory breathhold. The components of work of breathing, elastic and threshold are represented. (JPG $2451 \mathrm{~kb}$ )
Additional file 2: Formulas for estimation of lung mechanics in quasi - static conditions. (DOCX $15 \mathrm{~kb}$ )

Additional file 3: Correlations between changes in respiratory parameters and age and ideal body weight. (DOCX $15 \mathrm{~kb}$ )

\section{Abbreviations}

ARDS: Acute respiratory distress syndrome; $C_{R S}$ : Compliance respiratory system; CT: Computed tomography; EELV: End expiratory lung volume; iPEEP: Intrinsic positive pressure at the end of exhalation; $\mathrm{K}_{\mathrm{TE}}$ : Expiratory time constant; $\mathrm{K}_{\mathrm{T}}$ : Inspiratory time constant; MV: Mechanical ventilation; Paw: Airway pressure; PEEP: Positive pressure at the end of exhalation; PIP: Peak inspiratory pressure; $P_{\mathrm{PL}}$ : Plateau pressure; $\mathrm{Q}_{\mathrm{E}}$ : Maximum expiratory flow; $Q_{\text {: }}$ Maximum inspiratory flow; RawE: Resistance expiratory airway; Rawl: Resistance inspiratory airway; RR: Respiratory rate; tPEEP: Total positive pressure at the end of exhalation; VILI: Ventilator induced lung injury; $V_{T}$ : Tidal volume; ZEEP: Positive pressure at the end of exhalation set at 0 $\mathrm{CmH}_{2} \mathrm{O} ; \Delta \mathrm{P}$ : Driving pressure

\section{Acknowledgements}

'Not applicable'.

\section{Funding}

This work was supported by CONICYT \#1160631 (Dr. Cruces) and CONICYT. \#11160463 (Dr. Diaz) grants. These grants were involved in design of the study, collection of data, writing the manuscript and manuscript language edition services.

\section{Availability of data and materials}

The authors confirm that the data supporting the findings of this study are available within the article and its supplementary materials. Raw data generated cannot be publicly available due to concerns of privacy of research participants, but may be available from the corresponding author FD on request.

\section{Authors' contributions}

Study design: PC, SG, FC, JM, RH, FD; Measurements of respiratory mechanics: SG, FC, JM, RH; Statistic analysis: PC, BE, FD, SG; Writing the manuscript: PC, 
SG, BE, FD; Review of the manuscript: All authors. All authors read and approved the final manuscript.

\section{Ethics approval and consent to participate}

Institutional Review Board at Centro Hospitalario Pereira Rossell approved the study (\#2852015).

Written informed consent to participate was obtained from the parents/ guardians after preanesthetic interview by the PI of the study.

\section{Consent for publication}

Written consent was obtained from caregivers of included patients.

\section{Competing interests}

The authors declare that they have no competing interests.

\section{Publisher's Note}

Springer Nature remains neutral with regard to jurisdictional claims in published maps and institutional affiliations.

\section{Author details}

${ }^{1}$ Pediatric Intensive Care Unit, Hospital El Carmen de Maipú, Santiago, Chile. ${ }^{2}$ Centro de Investigación de Medicina Veterinaria, Escuela de Medicina Veterinaria, Facultad de Ecología y Recursos Naturales, Universidad Andres Bello, Santiago, Chile. ${ }^{3}$ Pediatric Intensive Care Unit, Centro Hospitalario Pereira Rossell, Montevideo, Uruguay. ${ }^{4}$ Department of Anesthesiology, Centro Hospitalario Pereira Rossell, Montevideo, Uruguay. ${ }^{5}$ Unidad de Cuidados Intensivos Pediátricos, Clínica Alemana de Santiago, Avda. Vitacura, 595 Santiago, Chile. ${ }^{6}$ Facultad de Medicina Clínica Alemana Universidad del Desarrollo, Santiago, Chile. ${ }^{7}$ Area de Cuidados Críticos, Hospital Padre Hurtado, Santiago, Chile.

\section{Received: 27 February 2018 Accepted: 9 October 2018} Published online: 24 October 2018

\section{References}

1. Slutsky AS, Ranieri VM. Ventilator-induced lung injury. N Engl J Med. 2013; 369:2126-36.

2. Donoso A, Cruces P. Daño pulmonar inducido por ventilación mecánica y estrategia ventilatoria convencional protectora. Rev Chil Pediatr. 2007;78: 241-52.

3. Bein T, Grasso S, Moerer O, Quintel M, Guerin C, Deja M, et al. The standard of care of patients with ARDS: ventilatory settings and rescue therapies for refractory hypoxemia. Intensive Care Med. 2016;42:699-711.

4. Imai Y, Kawano T, Miyasaka K, Takata M, Imai T, Okuyama K. Inflammatory chemical mediators during conventional ventilation and during high frequency oscillatory ventilation. Am J Respir Crit Care Med. 1994:150:1550-4.

5. Tusman G, Böhm SH, Warner DO, Sprung J. Atelectasis and perioperative pulmonary complications in high-risk patients. Curr Opin Anaesthesiol. 2012;25:1-10

6. Vargas M, Sutherasan Y, Gregoretti C, Pelosi P. PEEP role in ICU and operating room: from pathophysiology to clinical practice. ScientificWorldJournal. 2014;2014:852356.

7. Futier E, Constantin JM, Paugam-Burtz C, Pascal J, Eurin M, Neuschwander A et al. IMPROVE study group. A trial of intraoperative low-tidal-volume ventilation in abdominal surgery. N Engl J Med. 2013;369:428-37.

8. Wolthuis EK, Choi G, Dessing MC, Bresser P, Lutter R, Dzoljic M, et al, Mechanical ventilation with lower tidal volumes and positive end-expiratory pressure prevents pulmonary inflammation in patients without preexisting lung injury. Anesthesiology. 2008;108:46-54.

9. Barbosa FT, Castro AA. de Sousa-Rodrigues CF. positive end-expiratory pressure (PEEP) during anaesthesia for prevention of mortality and postoperative pulmonary complications. Cochrane Database Syst Rev. 2014;6:CD007922.

10. Severgnini P, Selmo G, Lanza C, Chiesa A, Frigerio A, Bacuzzi A, et al. Protective mechanical ventilation during general anesthesia for open abdominal surgery improves postoperative pulmonary function. Anesthesiology. 2013;118:1307-21.

11. Wahba RW. Perioperative functional residual capacity. Can J Anaesth. 1991 38:384-400
12. Fletcher ME, Stack C, Ewart M, Davies CJ, Ridley S, Hatch DJ, et al. Respiratory compliance during sedation, anesthesia, and paralysis in infants and young children. J Appl Physiol. 1985;70:1977-82.

13. Dobbinson TL, Nisbet HI, Pelton DA, Levison H. Functional residual capacity (FRC) and compliance in anaesthetized paralysed children. II. Clinical results. Can Anaesth Soc J. 1973;20:322-33.

14. Serafini G, Cornara G, Cavalloro F, Mori A, Dore R, Marraro G, et al. Pulmonary atelectasis during paediatric anaesthesia: CT scan evaluation and effect of positive end-expiratory pressure (PEEP). Paediatr Anaesth. 1999;9:225-8.

15. Trachsel D, Svendsen J, Erb TO. von Ungern-Sternberg BS. Effects of anaesthesia on paediatric lung function. Br J Anaesth. 2016:117:151-63.

16. Feldman JM. Optimal ventilation of the anesthetized pediatric patient. Anesth Analg. 2015:120:165-75.

17. Wanderer JP, Ehrenfeld JM, Epstein RH, Kor DJ, Bartz RR, FernandezBustamante $A$, et al. Temporal trends and current practice patterns for intraoperative ventilation at U.S. academic medical centers: a retrospective study. BMC Anesthesiol. 2015;15:40.

18. Kneyber MC. Intraoperative mechanical ventilation for the pediatric patient. Best Pract Res Clin Anaesthesiol. 2015;29:371-9.

19. Erranz B, Díaz F, Donoso A, Salomón T, Carvajal C, Torres MF, et al. Decreased lung compliance increases preload dynamic tests in a pediatric acute lung injury model. Rev Chil Pediatr. 2015;86:404-9.

20. Díaz F, Erranz B, Donoso A, Carvajal C, Salomón T, Torres M, Cruces P. Surfactant deactivation in a pediatric model induces hypovolemia and fluid shift to the extravascular lung compartment. Paediatr Anaesth. 2013;23:250-7.

21. Feldman JM. Optimal ventilation of the anesthetized pediatric patient. Anesth Analg. 2015;120:165-75

22. Peterson-Carmichael S, Seddon PC, Cheifetz IM, Frerichs I, Hall GL, Hammer J, et al. ATS/ERS working group on infant and young ChildrenPulmonary function testing. An official American Thoracic Society/EuropeanRespiratory society workshop report: evaluation of respiratory mechanics andFunction in the pediatric and neonatal intensive care units. Ann Am Thorac Soc. 2016;13:S1-11.

23. Kaditis AG, Motoyama EK, Zin W, Maekawa N, Nishio I, Imai T, et al. The effect of lung expansion and positive end-expiratory pressure on respiratory mechanics in anesthetized children. Anesth Analg. 2008;106:775-85.

24. Cruces P, González-Dambrauskas S, Quilodrán J, Valenzuela J, Martínez J, Rivero N, et al. Respiratory mechanics in infants with severe bronchiolitis on controlled mechanical ventilation. BMC Pulm Med. 2017:17:129.

25. Jonson B, Richard JC, Straus C, Mancebo J, Lemaire F, Brochard L. Pressurevolume curves and compliance in acute lung injury: evidence of recruitment above the lower inflection point. Am J Respir Crit Care Med. 1999;159:1172-8.

26. Protti A, Maraffi T, Milesi M, Votta E, Santini A, Pugni P, et al. Role of strain rate in the pathogenesis of ventilator-induced lung edema. Crit Care Med. 2016:44:e838-45.

27. Amato MB, Meade MO, Slutsky AS, Brochard L, Costa EL, Schoenfeld DA, et al. Driving pressure and survival in the acute respiratory distress syndrome. N Engl J Med. 2015;372:747-55.

28. Lucangelo $U$, Bernabé $F$, Blanch L. Respiratory mechanics derived from signals in the ventilator circuit. Respir Care. 2005;50:55-65.

29. Neto AS, Hemmes SN, Barbas CS, Beiderlinden M, Fernandez-Bustamante A Futier $E$, et al. Association between driving pressure and development of postoperative pulmonary complications in patients undergoing mechanical ventilation for general anaesthesia: a meta-analysis of individual patient data. Lancet Respir Med. 2016;4:272-80

30. Wirth S, Artner L, Broß T, Lozano-Zahonero S, Spaeth J, Schumann S, et al. Intratidal recruitment/derecruitment persists at low and moderate positive end-expiratory pressure in paediatric patients. Respir Physiol Neurobiol. 2016;234:9-13.

31. Rausch SMK, Haberthur D, Stampanoni M, Schittny JC, Wall WA. Local strain distribution in real three-dimensional alveolar geometries. Ann Biomed Eng. 2011;39:2835-43.

32. Webb HH, Tierney DF. Experimental pulmonary edema due to intermittent positive pressure ventilation with high inflation pressures. Protection by positive end-expiratory pressure. Am Rev Respir Dis. 2003;1974:556-65. 